\title{
CONCENTRATIONS OF FLUOTHANE VAPOUR PRODUCED BY VAPORIZING BOTTLES OF SOME STANDARD ANAESTHETIC MACHINES ${ }^{*}$
}

J. G. Robson, F.F.A.R.C.s. (ENG.), and Peter Welt, M.D. $†$

THE FIGUREs sHow the concentration of Fluothane vapour delivered by the vaporizing bottles noted on each figure, the conditions being stated.

The concentrations were estimated by means of a katharometer which was calibrated with known mixtures of Fluothane in oxygen with oxygen as the reference gas. The mixtures were prepared by vaporizing a known weight of Fluothane with a measured volume of oxygen into a fifty-litre polyvinyl chloride bag. The calculation to volume/volume was made with the assumption that the mixture was an ideal gas. The response of the kathardmeter was shown to be linear within the required range and it was therefore sufficient to use one known mixture and the zero to contruct the calibration curve for each test. The stability of the instrument was good. The average error of estimation was \pm 1.8 per cent of the percentage stated. It is of interest to note that the concentrations given for these vaporizers, if corrected for the temperature change of the Fluothane liquid, show that the fall in temperature is almost solely responsible for the fall in

MARRETT TRILENE BOTTLE. 20 OUNCES FLUOTHANE.

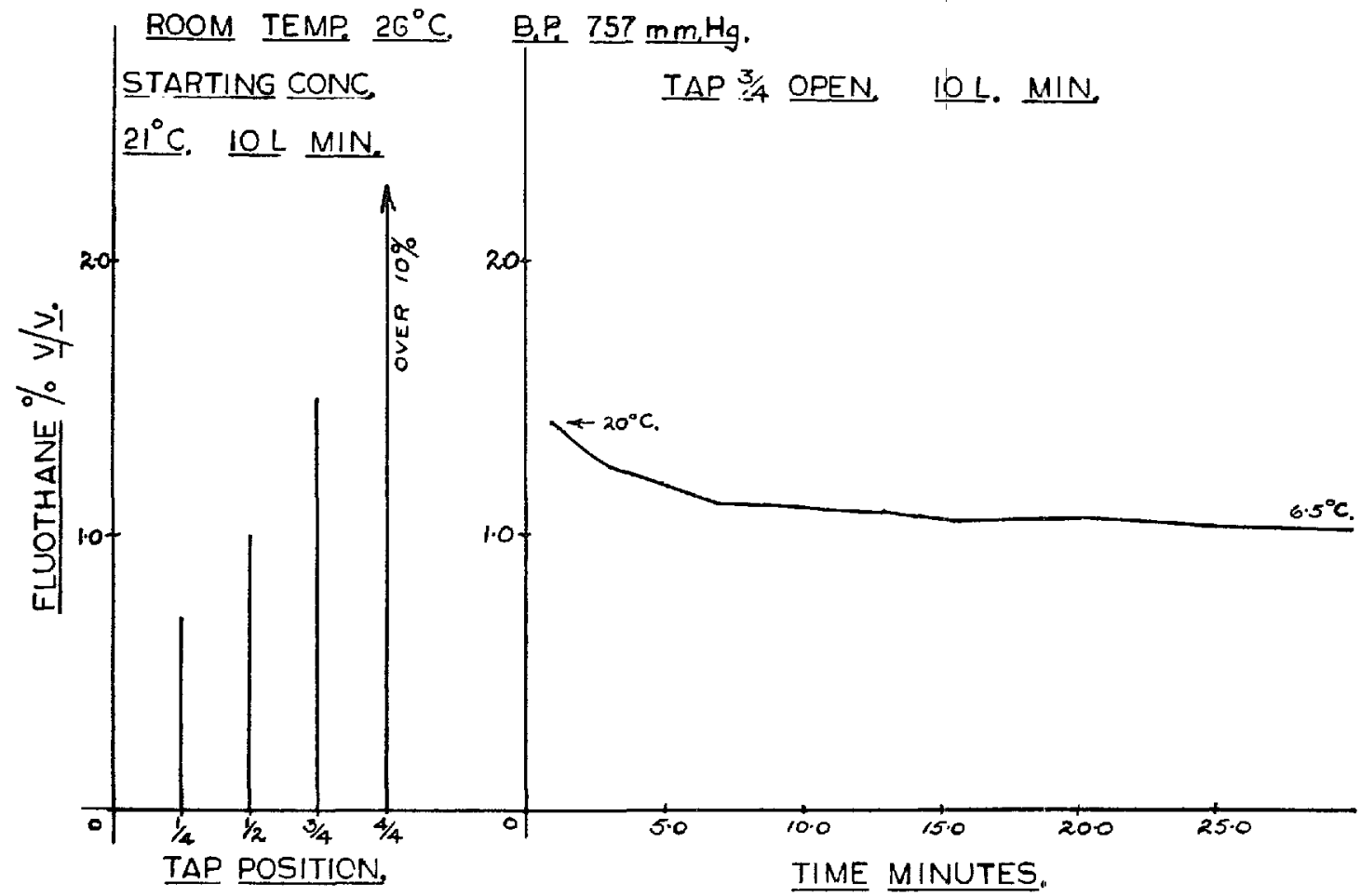

Figure 1

'Presented at the Annual Meeting, Canadian Anaesthetists' Society, Saskatoon, Sask., 24 June, 1957.

†Wellcome Research Department of Anaesthesia, McGill University, Montreal. 
ROBSON AND WELT: CONCENTRATIONS OF FLUOTHANE VAPOUR

BOYLES TRILENE BOTTLE. 100 CC FLUOTHANE. PLUNGER UP. ROOM IEMP $29^{\circ} \mathrm{C} \quad$ B.P $757 \mathrm{~mm} / \mathrm{gh}$

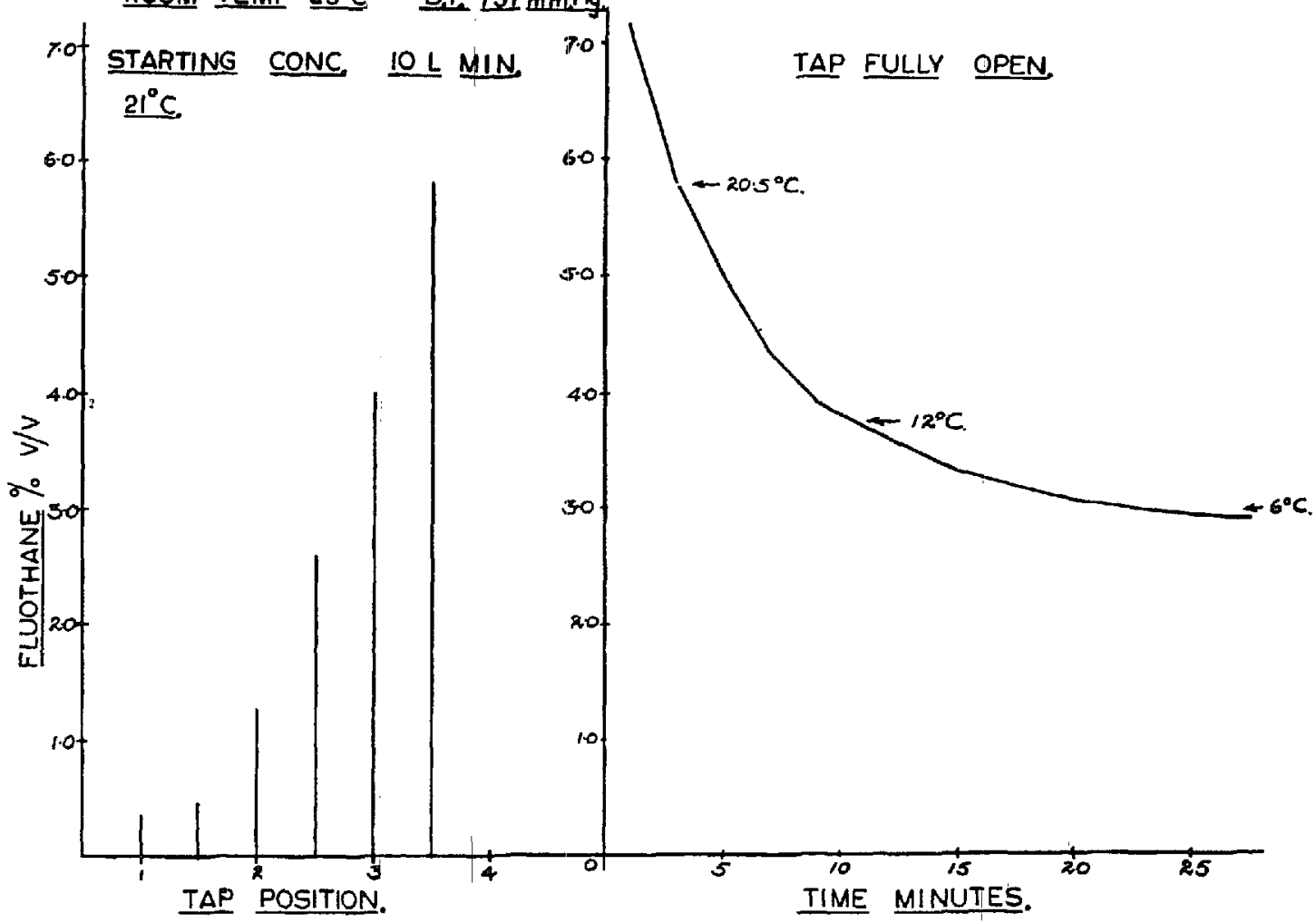

Figure 2

TRIMAR BOTTLE. FILLED TO LINE. ROOM TEMP $30^{\circ} \mathrm{C}$. BP $757 \mathrm{mmHg}$.

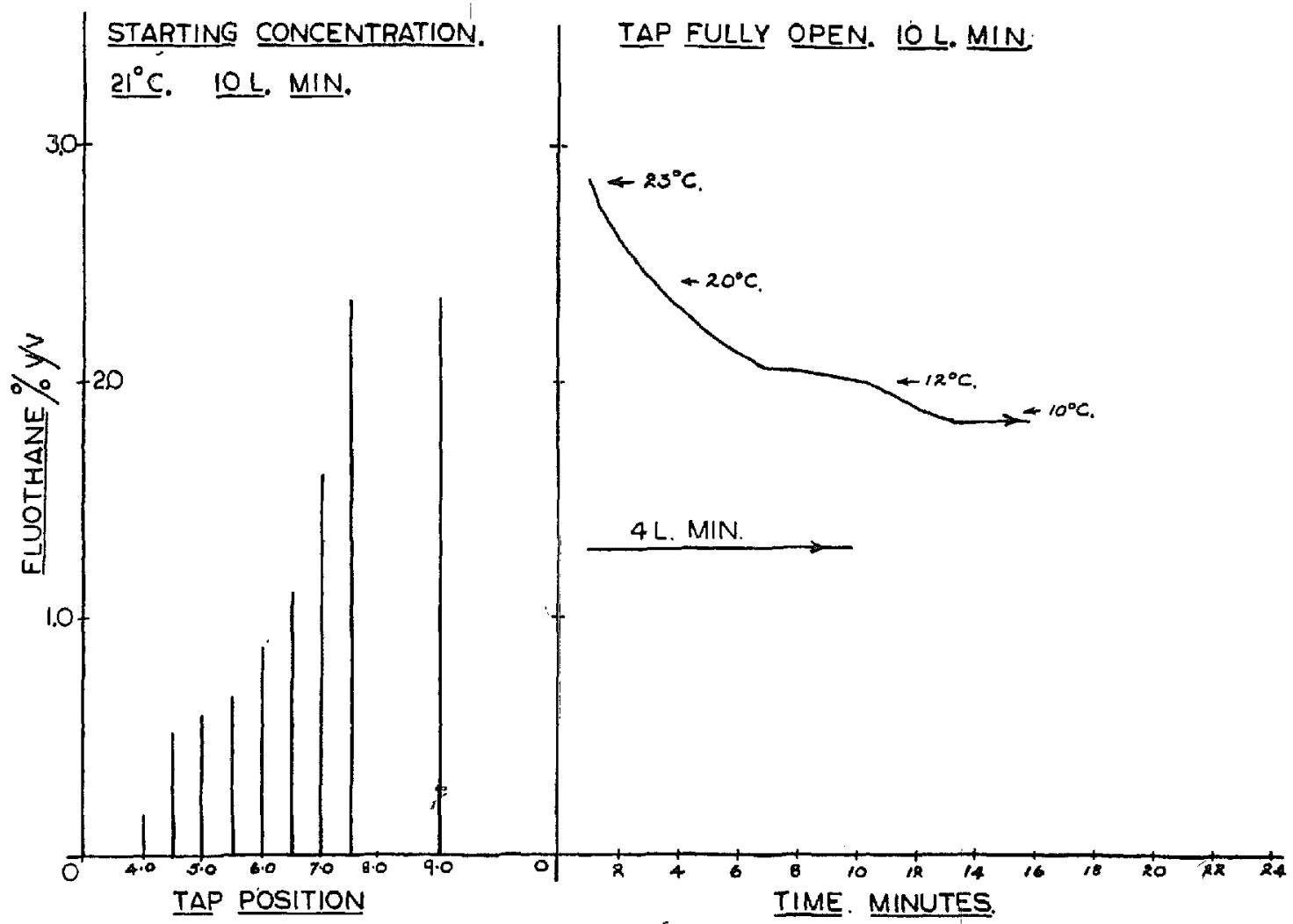

Figure 3 


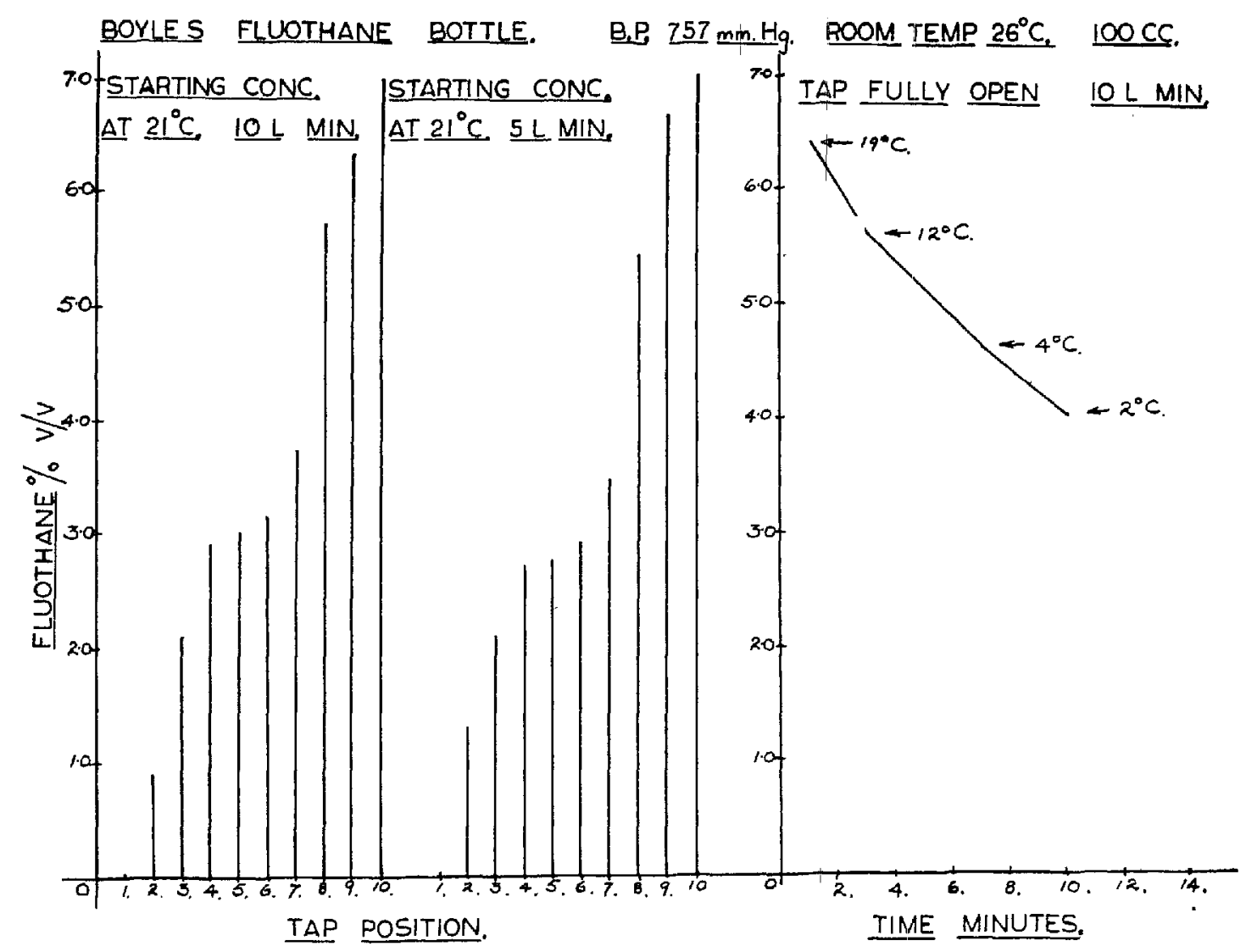

FIGURE 4

concentration. If one cares to insert a thermometer into the bottle, it is possible to find the issuing concentration from its reading and the curve, provided that the conditions of flow and the tap setting are similar.

The starting concentrations have been corrected to the stated temperature by means of the following formula (using $21^{\circ} \mathrm{C}$. as the temperature):

$$
\mathrm{C}_{21}{ }^{\circ}=C_{\mathrm{x}^{\circ}} \frac{p_{21}^{\circ}}{p_{x^{\circ}}^{\circ}}
$$

where $\mathrm{C}_{x^{\circ}}$ concentration estimated at $x^{\circ} \mathrm{C} . ; \mathrm{C}_{21^{\circ}}$ concentration at $21^{\circ} \mathrm{C}$; $p_{x^{\circ}}$ vapour pressure at $x^{\circ} \mathrm{C}$; $p_{21^{\circ}}$ vapour pressure at $21^{\circ} \mathrm{C}$.

The vapour pressure $p$ at the absolute temperature $T$ can be calculated from the formula:

$$
\log p=7.732-\frac{1564}{T}
$$

The accuracy of this correction depends upon the accuracy of the temperature measurement and the average error was \pm 3.5 per cent of the stated percentage.

\section{SUMMARY}

The concentrations of Fluothane vapor produced by some vaporizing bottles are given. These were estimated by means of a katharometer. 